Revista Eletrônica do Mestrado em Educação Ambientaך

\title{
Indícios da formação de emoções provocadas por um estudo da realidade: articulações entre a Neurociência e a perspectiva Estético-ambiental da Educação
}

\author{
Ronan Moura Franco ${ }^{1}$ \\ Escola Municipal de Ensino Fundamental (EMEF) Moacyr Ramos Martins \\ https://orcid.org/0000-0001-7237-2258 \\ Elena Maria Billig Mello ${ }^{2}$ \\ Universidade Federal do Pampa \\ https://orcid.org/0000-0003-0366-3021 \\ Diana Paula Salomão de Freitas ${ }^{3}$ \\ Universidade Federal do Pampa \\ https://orcid.org/0000-0001-6944-2219
}

\begin{abstract}
Resumo: Este trabalho tem por objetivo apresentar os resultados de uma pesquisa do tipo intervenção pedagógica, que investigou indícios de estímulos emocionalmente competentes e emoções provocados por um estudo da realidade, na perspectiva da Educação Estético-ambiental, argumentando sobre a relevância de práticas educativas que considerem os aspectos neurobiológicos dos envolvidos. Para tanto, foram planejados e executados quatro encontros, com duas turmas de Ensino Médio de uma escola estadual de Uruguaiana/RS, envolvendo 37 estudantes, que produziram 87 registros escritos. Estes registros foram apreciados pelo método da Análise Textual Discursiva, do qual emergiram três categorias. Como resultados, argumentamos que a realização de práticas como a investigação da realidade é capaz de estimular, de forma emocional, mobilizando para a aprendizagem, que acontecerá de forma contextualizada quando articulada à realidade contraditória, vivida por aqueles que a estudam.
\end{abstract}

\footnotetext{
${ }^{1}$ Mestre em Ensino de Ciências, Especialista em Neurociência aplicada à Educação e Licenciado em Ciências da Natureza (Unipampa/RS). Atualmente é Professor de Ciências na Escola Municipal de Ensino Fundamental Moacyr Ramos Martins, Professor de Física no Colégio Marista Sant'Ana. e-mail: rmourafranco@gmail.com.

${ }^{2}$ Professora associada da Universidade Federal do Pampa (UNIPAMPA), professora permanente dos Programa de Pósgraduacão em Ensino e curso de especializacão em Neurociência ablicada à Educacão pela UNIPAMPA. É mestra em Educação pela Universidade Federal de Santa Maria (UFSM) e doutora em Educação pela Universidade Federal do Rio Grande do Sul (UFRGS). e-mail: profelena@gmail.com.

${ }^{3}$ Professora adiunta da Universidade Federal do Pampa (UNIPAMPA), professora permanente dos Programas de Pós graduação em Ensino, mestrado profissional em Ensino de Ciências (PPGMPEC) e do curso de especialização em Educacão e diversidade cultural (UNIPAMPA). Possui mestrado em Educacão Ambiental e doutorado em Educação em Ciências ambos pela Universidade Federal de Rio Grande (FURG). e-mail: disalomao@gmail.com.
}

Rev. Eletrônica Mestr. Educ. Ambient. Rio Grande, v. 36, n. 3, p. 43-64, set./dez. 2019. 
Palavras-chave: Emoções. Estímulo emocionalmente competente. Percepção. Educação estéticoambiental.

\title{
Acusos de la formación de emociones causadas por un estudio de la realidad: articulaciones entre la neurociencia y la perspectiva estético-ambiental de la educación
}

\begin{abstract}
Resumen: Este trabajo tiene por objetivo presentar los resultados de una investigación de tipo intervención pedagógica, que investigó indicios de estímulos emocionalmente competentes y emociones provocados por un estudio de la realidad, en la perspectiva de la Educación Estéticoambiental, argumentando sobre la relevancia de prácticas educativas investigativas que consideren los aspectos neurobiológicos de los involucrados. Para ello, fueron planeados y ejecutados cuatro encuentros, con alumnos de dos clases de Enseñanza Media de una escuela pública de Uruguaiana/RS, involucrando a 37 estudiantes, que produjeron 87 registros escritos. Estos registros fueron apreciados por el método de análisis textual discursivo, del cual surgieron tres categorias. Como resultados, argumentamos que la realización de prácticas como la investigación de la realidad es capaz de estimular, de forma emocional, movilizando para el aprendizaje, que ocurrirá de forma contextualizada cuando articulada a la realidad contradictoria, vivida por aquellos que la estudian.
\end{abstract}

Palabras-clave: Emociones. Estímulo emocionalmente competente. Percepción. Educación estético-ambiental.

\section{Evidence of the formation of emotions caused by a study of reality: articulations between neuroscience and the aesthetic-environmental perspective of education}

\begin{abstract}
This work aims to present the results of a research of the type pedagogical intervention, which investigated evidence of emotionally competent stimuli and emotions brought about by a study of reality, from the perspective of Aesthetic-Environmental Education, in order to argue about the relevance of investigative educational practices that consider the neurobiological aspects of those involved. For that, four meetings were planned and executed, with two high school classes from a state school in Uruguaiana/ RS, involving 37 students, who produced 87 written records. These records were appreciated by the Discursive Textual Analysis method, from which three categories emerged. As results, we argue that the realization of practices such as the investigation of reality is capable of stimulating, emotionally, mobilizing us for learning, which will happen in a contextualized and articulated way to the contradictory reality experienced by those who study it.
\end{abstract}

Key-words: Emotions. Emotionally competent stimulus. Perception. Aesthetic-environmental education.

\section{INTRODUÇÃO}

Em uma sociedade marcada por injustiças sociais e exploração de ordem ambiental, cada vez mais os sujeitos são impelidos a tomar decisões frente aos acontecimentos que formam a pauta diária das nossas vivências. Com isso, faz-se indispensável que a escola básica ocupe lugar de protagonismo na realização de práticas educativas, colaborando no desvelamento das injustiças como as mencionadas acima, 
assumindo a educação, enquanto prática que se concretiza nas relações sociais que transcendem o espaço e o tempo escolares (BRASIL, 2010a, 2010b).

Para fundamentar este estudo, assumimos a noção de estética como perspectiva de educação que pauta-se pelo que foi apresentado por Silveira (2015), para quem “(...) a esfera do estético abrange todo o conteúdo e as nuances do relacionamento emocional do indivíduo com a realidade circundante" (SILVEIRA, 2015, p.37). Não se refere apenas à esfera das artes, mas à sensibilidade humana em geral, o que seria a capacidade de perceber e sentir. Assim, assumimos a necessidade de educar esteticamente, construindo um modo de enriquecer o universo emocional das pessoas, criando desejos, necessidades, vontades e atitudes para que se mobilizem frente às necessárias transformações históricosociais atuais (ESTÉVEZ, 2014).

Silveira (2015) afirma que devemos, especialmente enquanto educadores, assumir uma postura transformadora e de enfrentamento frente à crise socioambiental atual, compreendida enquanto degradação da natureza humana e não humana, que gera empobrecimento natural e cultural como resultado de relações alienantes provocadas pelo sistema capitalista. Nesta esteira de conhecimentos, que compõem a educação em uma perspectiva estético-ambiental, consideramos então, que compreender os processos educativos de investigação da realidade, a partir da Investigação Temática freireana e fazer desses processos momentos em que os sujeitos envolvidos consigam estabelecer relação dos conhecimentos construídos com a complexidade das relações com que estes se estabelecem, é desafio para as Escolas preocupadas em desenvolver práticas educativas crítico-transformadoras.

Neste artigo, apresentamos os resultados de uma pesquisa do tipo intervenção pedagógica, conduzida pelo seguinte questionamento: como uma intervenção pedagógica, planejada a partir do estudo da realidade, promove estímulos emocionalmente competentes e emoções nos sujeitos participantes? Para responder ao questionamento, objetivamos com este estudo investigar indícios de estímulos emocionalmente competentes (EEC) e emoções provocados por um estudo da realidade, que integra as etapas do processo de Investigação Temática (IT) freireana, que, desde o planejamento, foi desenvolvido articulando os fundamentos neurobiológicos das emoções à uma perspectiva estético-ambiental de educação.

Construímos este artigo tomando por referência o estudo teórico-reflexivo de Salomão de Freitas, Motta e Mello-Carpes (2014), em que as autoras defendem que os sujeitos quando participam de forma ativa do processo de IT “(...) recebe mais EEC, Rev. Eletrônica Mestr. Educ. Ambient. Rio Grande, v. 36, n. 3, p. 43-64, set./dez. 2019. E-ISSN 1517-1256 
porque, ao participar das relações que constituem a situação investigada, seus sentimentos e emoções são mobilizados, o que favorece seu processo de aprendizagem” (p.117). Estes autores estabeleceram uma relação teórica entre o processo de IT freireana e as bases neurobiológicas da aprendizagem, a partir da qual realizamos uma intervenção pedagógica que se aproximou do que foi descrito no referido estudo. Acrescentamos ainda:

\begin{abstract}
(...) a participação dos sujeitos em experiências de investigação para melhor compreensão e conscientização dos temas que estudarão provocará maiores emoções e estímulos do que a visualização de imagens ou, ainda, textos que abordem superficialmente o tema, sem contextualizá-lo. Demonstra-se, assim, a necessidade dos educadores em compreender melhor as possibilidades e limitações da utilização de imagens como recurso pedagógico (SALOMÃO DE FREITAS, MOTTA e MELLO-CARPES, 2014, p.116).
\end{abstract}

$\mathrm{Na}$ pesquisa que se apresenta, nos aprofundamos a compreender o funcionamento e implicações das emoções, fazendo assim um recorte no amplo espectro de estudo das Neurociências. Compreender o estudo das bases biológicas das emoções, assim como entender que seu valor depende das circunstâncias atuais “(...) oferece oportunidades novas para a compreensão moderna do comportamento humano" (DAMÁSIO, 2003, p.48). Isso subsidia este estudo quando, junto do fundamento estético-ambiental da educação, instiga-nos a contestar processos de degradação do meio ambiente e, consequentemente, do ser humano.

Contextualizamos que a pesquisa foi realizada em uma escola estadual de nível médio, localizada na periferia do município de Uruguaiana, Rio Grande do Sul. A organização curricular dessa escola está fundamentada nos princípios da pedagogia freireana de: participação, amorosidade, dialogicidade, rigorosidade, humanização, autonomia, criticidade e ética (PPP, 2013). Anualmente, a escola realiza o estudo da realidade, momento no qual professores e estudantes: a) refletem sobre a importância da realização da pesquisa; b) planejam roteiro com questões para serem perguntadas para pessoas da localidade, de acordo com os focos ${ }^{4}$ de cada ano do Ensino Médio; c) saem juntos da escola para investigar a realidade da comunidade, por meio das entrevistas realizadas por meio das perguntas elaboradas e anotação das respostas; d) retornam à escola para analisar falas significativas; e) mapeiam assuntos comuns, mencionados nas

\footnotetext{
${ }^{4}$ A organização curricular da escola dispõe sobre $10(\mathrm{dez})$ focos que fundamentam as práticas educativas de cada ano do ensino médio, sendo que cada ano apresenta 2 (dois) focos e para o terceiro ano os respectivos focos são: Foco 5: Políticas públicas em vista da qualidade de vida e Foco 6: Alternativas de desenvolvimento, perspectivas futuras (PPP, 2013).
}

Rev. Eletrônica Mestr. Educ. Ambient. Rio Grande, v. 36, n. 3, p. 43-64, set./dez. 2019.

E-ISSN 1517-1256 
entrevistas. O conteúdo das entrevistas serve como base para o planejamento do trabalho pedagógico, pois oferece um diagnóstico à prática de sala de aula (PPP, 2013).

O estudo da realidade é uma etapa do processo de IT, apresentado por Freire no capítulo três da Pedagogia do Oprimido (2011), no qual o autor descreve, justifica e exemplifica esse processo, organizado nas etapas de Investigação, Tematização e Problematização que são operacionalizadas em: a) levantamento preliminar da realidade; b) codificação; c) descodificação; d) redução temática, e) desenvolvimento do trabalho em sala de aula (FREIRE, 2011). O estudo que apresentamos se caracteriza como um recorte do processo, concentrado na etapa de Investigação, especificamente no levantamento preliminar da realidade.

Frente ao exposto, mencionamos que este trabalho está organizado em quatro partes, sendo que, nos itens subsequentes, trazemos o percurso metodológico, a discussão dos resultados e as considerações finais.

\section{PERCURSO METODOLÓGICO}

A pesquisa foi realizada a partir de uma abordagem qualitativa, considerando que interpretou um conjunto de fenômenos humanos que compõem a realidade social. $\mathrm{O}$ universo da produção humana é compreendido como o mundo das relações, das representações e das intencionalidades. Logo, dada a complexidade desse universo humano, entendemos a pesquisa qualitativa (MINAYO, 1994) como a mais coerente para o desenvolvimento deste trabalho. Ainda, caracterizou-se como do tipo intervenção pedagógica, o que, segundo Damiani e colaboradores, objetiva “(...) contribuir para a produção de conhecimento pedagógico e levar à diminuição da distância entre a prática educacional e a produção acadêmica" (2013, p. 58). Para isso, os autores propõem o desenvolvimento de práticas investigativas envolvendo os momentos: "o planejamento e a implementação de interferências (mudanças, inovações) - destinadas a produzir avanços, melhorias, nos processos de aprendizagem dos sujeitos que delas participam - e a posterior avaliação dos efeitos dessas interferências" (DAMIANI et al, 2013, p.58). Para sua efetivação devemos considerar os métodos de intervenção propriamente dita e avaliação da intervenção.

O método da intervenção propriamente dita, nesta pesquisa, compreendeu o planejamento e a implementação do estudo da realidade, planejados e desenvolvidos em quatro encontros - num total de oito horas-aula, juntamente com os professores regentes 
de duas turmas, totalizando 37 alunos do terceiro ano do Ensino Médio, constituindo estes os sujeitos participantes do processo investigativo aqui apresentado. $\mathrm{O}$ espaço em que a intervenção foi realizada é denominado "Tempo comunidade", que se caracteriza como um momento da semana letiva, em que dois ou mais educadores ocupam a mesma turma, desenvolvendo um trabalho coletivo e interdisciplinar (PPP, 2013).

O método da intervenção propriamente dita foi organizado considerando a primeira etapa do processo de estudo da realidade, quando as aulas foram organizadas tomando por referência a tríade dialética proposta por Vasconcelos (1992), composta pelos momentos de: i) síncrese - entendido como a problematização inicial e mobilização para o conhecimento, partindo de questionamentos norteadores; ii) análise - construção, discussão e reconstrução do conhecimento com apoio de recursos e estratégias pedagógicas e iii) síntese - reorganização do conhecimento, pelos participantes, a partir de questões que sistematizam o que foi abordado, conforme pode ser observado na tabela abaixo.

Quadro 1 - Organização e caracterização dos encontros da etapa do estudo da realidade.

\begin{tabular}{|c|c|c|}
\hline & & \\
\hline \multirow{2}{*}{$\begin{array}{l}\text { Encontro } 1 \\
\text { Abordagem sobre o } \\
\text { que é pesquisa, o } \\
\text { que é a Pesquisa da } \\
\text { Realidade e o } \\
\text { significado do } \\
\text { desenvolvimento } \\
\text { desta prática para a } \\
\text { escola. }\end{array}$} & \multirow{2}{*}{$\begin{array}{l}\text { Refletir sobre os } \\
\text { entendimentos de } \\
\text { pesquisa, apontando a } \\
\text { importância da } \\
\text { pesquisa da realidade } \\
\text { no desenvolvimento } \\
\text { das práticas educativas } \\
\text { da escola. }\end{array}$} & $\begin{array}{l}\text { empírica com sc } \\
\text { entendimentos. }\end{array}$ \\
\hline & & $\begin{array}{l}3^{\circ} \text { - Escrita reflexiva que art } \\
\text { compreensão de pesquisa } \mathrm{c} \\
\text { processo de investigação da realid }\end{array}$ \\
\hline \multirow{3}{*}{$\begin{array}{l}\text { Encontro } 2 \\
\text { Elaboração } \\
\text { questões das } \\
\text { compõem o roteiro } \\
\text { de investigação, } \\
\text { construídos pelos } \\
\text { alunos de acordo } \\
\text { com os focos do } 3^{\circ} \\
\text { (terceiro) ano do } \\
\text { Ensino Médio, }\end{array}$} & \multirow{3}{*}{ 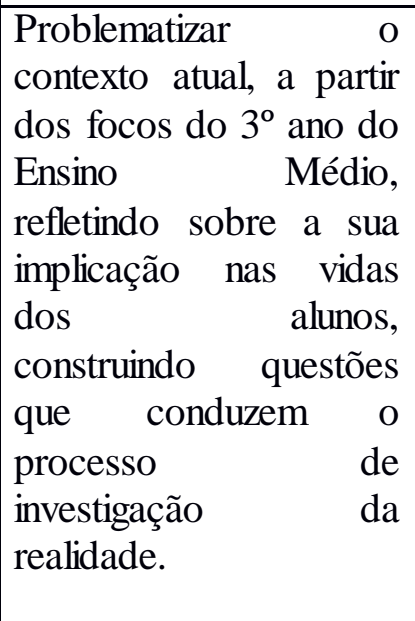 } & rteiam \\
\hline & & $\begin{array}{l}2^{\circ} \text { - Leitura de um texto sobre trabalho e } \\
\text { perspectivas futuras com socialização } \\
\text { coletiva dos entendimentos; Construção } \\
\text { coletiva das perguntas para a realização } \\
\text { das entrevistas para a pesquisa da } \\
\text { realidade. }\end{array}$ \\
\hline & & $\begin{array}{l}3^{\circ} \text { - Escrita reflexiva sobre as } \\
\text { oportunidades oferecidas de emprego e } \\
\text { estudos para os alunos no contexto de } \\
\text { Uruguaiana/RS. }\end{array}$ \\
\hline
\end{tabular}

Rev. Eletrônica Mestr. Educ. Ambient. Rio Grande, v. 36, n. 3, p. 43-64, set./dez. 2019. 


\begin{tabular}{|c|c|c|}
\hline $\begin{array}{l}\text { investiga } \\
\text { zando } \\
\text { evistas } \\
\text { luzidas atr } \\
\text { ques }\end{array}$ & $\begin{array}{l}\text { vestigar o contexto } \\
\text { n que a escola está } \\
\text { serida, realizando } \\
\text { trevista com os } \\
\text { oradores dos bairros } \\
\text { le circundam } \text { e } \\
\text { mpõem } \\
\text { munidade escolar. }\end{array}$ & $\begin{array}{l}\text { alunos e professores da escola para a } \\
\text { realização das entrevistas com } \\
\text { moradores dos principais bairros que } \\
\text { compõem a comunidade escolar, } \\
\text { experenciando as condições de vida e as } \\
\text { contradições dos contextos investigados. }\end{array}$ \\
\hline \multirow{3}{*}{\begin{tabular}{lrr} 
Encontro & \multicolumn{1}{c}{4} & - \\
Reflexão & sobre & a \\
realização & da \\
pesquisa, a & partir \\
da saída & à \\
comunidade, \\
retomando
\end{tabular}} & \multirow{3}{*}{ 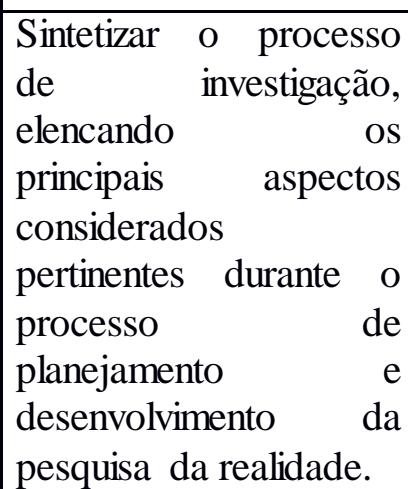 } & 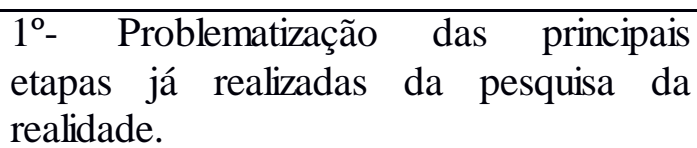 \\
\hline & & $\begin{array}{l}2^{\circ} \text { - Socialização das percepções dos } \\
\text { alunos sobre as etapas, com ênfase na } \\
\text { saída à comunidade para realização das }\end{array}$ \\
\hline & & $\begin{array}{l}\text { a sobre os principais } \\
\text { pelos alunos sobre as }\end{array}$ \\
\hline
\end{tabular}

Fonte: autoria própria.

O método de avaliação da intervenção apresenta como objetivo “(...) descrever os instrumentos de coleta e análise de dados utilizados para capturar os efeitos da intervenção" (DAMIANI et al, 2013, p.62). Nesta pesquisa, a avaliação da intervenção foi compreendida a partir da análise dos registros reflexivos escritos pelos alunos - corpus de análise - produzidos com o auxílio de roteiros que continham perguntas norteadoras, posteriormente examinadas à luz do referencial teórico que fundamentou o estudo.

Os instrumentos de produção de informação/coleta de dados foram 87 registros escritos durante as etapas organizadas nos quatro encontros do estudo da realidade. Os registros escritos se configuraram como um instrumento que melhor se adequou a proposta de intervenção pedagógica, pois estes são capazes de promover relações estéticas, produzindo cultura por meio das atividades de leitura e escrita, conforme apontam as autoras "Desta forma, este ser se reconhece enquanto leitor/escritor e viceversa, alguém que ao mesmo tempo produz cultura e por esta é produzido" (MUNHOZ e ZANELLA, 2008, p.293).

Estas informações foram analisadas por procedimentos descritos na metodologia de Análise Textual Discursiva (ATD), proposta por Moraes e Galiazzi (2007), compreendido enquanto um processo que integra a análise e síntese das informações, objetivando desenvolver uma leitura rigorosa e aprofundada de conjuntos de materiais 
textuais, descrevendo e interpretando, no sentido de “(...) atingir uma compreensão mais complexa dos fenômenos e dos discursos" (MORAES e GALIAZZI, 2007, p.114). Seguindo as orientações dos autores supracitados, as etapas da análise compreenderam:

a) organização e leitura atenta dos registros escritos, numerados, de 1 a 37, considerando o número de alunos participantes;

b) desconstrução dos registros, em que destacamos excertos que responderam a pergunta que revelou nossa intencionalidade de pesquisa de buscar nos registros escritos quais as expressões de emoções, sentidas pelos estudantes durante o processo de planejamento e realização do estudo da realidade;

c) unitarização dos excertos com sentido em si, destacados, seguidos de codificação, momento em que as unidades foram numeradas de acordo com o participante que elaborou o registro, o número do encontro e o número da unidade de significado que integrou o registro. Por exemplo: "E7.2.1" significa que, este registro foi produzido pelo aluno participante "sete", no encontro "dois" e que esta é a primeira unidade de significado destacada neste registro;

d) categorização das unidades de significado, num processo de agrupamento dos escritos com semelhança de conteúdo, o que resultou em três categorias emergentes. São elas: 1) $\mathrm{O}$ estudo da realidade como experiência estética provocadora de estímulos emocionalmente competentes, 2) A percepção sensível do contexto investigado e 3) O reconhecimento de emoções no estudo da realidade;

e) produção de metatexto, processo de construção elaboração de texto resultante dos procedimentos de análise, constituído pela argumentação teórica e reflexiva das categorias emergentes identificadas no processo de análise, articulando fundamentos neurobiológicos das emoções a uma perspectiva estético-ambiental da Educação.

Destacamos que este trabalho está vinculado a uma pesquisa mais ampla intitulada "Inovação pedagógica na formação de profissionais do magistério/da educação", aprovada pela Comissão de Ética em Pesquisa (CEP), parecer consubstanciado número 1.867.153 e registrado na Plataforma Brasil com Certificado de Apresentação para Apreciação Ética (CAAE) de número 56831616.3.0000.532.

\section{ARTICULAÇÕES ENTRE O FUNDAMENTO NEUROBIOLÓGICO DAS EMOÇÕES E A PERSPECTIVA ESTÉTICO-AMBIENTAL NA EDUCAÇÃO}


Nesta seção do trabalho apresentamos os resultados e as reflexões possíveis e necessárias, buscando articular aspectos teóricos da perspectiva estético-ambiental da educação com o fundamento neurobiológico das emoções. Partimos do entendimento contido no argumento de Salomão de Freitas, Motta e Mello-Carpes (2014) para quem "Os sujeitos aprendem aquilo que os emociona, que os sensibiliza" (p.120), constrú́mos o argumento de que os sujeitos necessitam experienciar as situações reais, sentindo seus estímulos de forma a perceber sensivelmente, e assim, mobilizarem-se na transformação da realidade estudada.

Assim, a discussão de resultados aqui apresentada está dividida em três categorias teórico-práticas e reflexivas, que se completam e obedecem à sequência de processos e fenômenos neuronais que resultam nas emoções, a partir da formação do estímulo, percebido sensivelmente pelos sentidos (DAMÁSIO, 1994; 2003; BISPO, 2003). As categorias discutidas a seguir foram construídas, a partir dos registros escritos reflexivos que evidenciam o que Bispo (2003) chamou de "memória autobiográfica", pois conta experiências vivenciadas, assim como projeta expectativas e desejos daqueles que lembram. O autor define a "memória autobiográfica" como sendo aquela constituída pelas memórias contidas na “(...) experiência individual do passado vivido e do futuro antevisto e tem como base os aspectos invariáveis da biografia de um indivíduo. Ela cresce continuamente com a experiência de vida e pode ser parcialmente remodelada para refletir novas experiências" (BISPO, 2003, p.297).

A memória, segundo Izquierdo é o processo de aquisição, formação, conservação e evocação de determinadas informações, sendo que “(...) a aquisição é também chamada de aprendizagem: só se 'grava' aquilo que foi aprendido. A evocação é também chamada de recordação, lembrança, recuperação. Só lembramos aquilo que gravamos, aquilo que foi aprendido" (IZQUIERDO, 2002, p. 09). Essas memórias que remontam às experiências vivenciadas pelos estudantes, expressas na forma de escritas reflexivas, evidenciaram aspectos percebidos de forma sensível, emocional da realidade e suas contradições ambientais e sociais, visto que “(...)a memória pode também provocar emoções à luz da consciência" (DAMÁSIO, 2003, p.64). Complementando, Salomão de Freitas, Motta e Mello-Carpes (2014) afirmam que a presença das emoções irá favorecer a formação das memórias e, dessa forma, o aprendizado, sendo “(...)muito mais fácil para nós recordarmos um evento ou um conteúdo que aprendemos em um contexto emocional mais intenso do que aqueles aprendidos em um contexto pouco significativo" (p. 116).

Rev. Eletrônica Mestr. Educ. Ambient. Rio Grande, v. 36, n. 3, p. 43-64, set./dez. 2019. E-ISSN 1517-1256 


\section{O estudo da realidade como experiência estética provocadora de estímulos emocionalmente competentes}

Damásio (2003) afirma que "A cadeia de fenômenos que leva à emoção inicia-se com um estímulo-emocionalmente-competente" (p. 65), desde então, interpretamos a fundamental e indispensável associação entre EEC e as emoções. Os EEC são definidos pelo autor supracitado como aqueles capazes de provocar um estado emocional no sujeito (DAMÁSIO, 2003). Esta definição é importante na medida em que Izquierdo (2002, p. 09) afirma que “(...)os maiores reguladores da aquisição, da formação e da evocação das memórias são justamente as emoções e os estados de ânimo".

Cosenza e Guerra nos dizem que são os órgãos dos sentidos que recebem as informações relevantes até o cérebro por meio de circuitos neuronais. Se esse estímulo é considerado importante, com valor emocional, é captado, podendo mobilizar a atenção e atingir as regiões corticais específicas, local onde é percebido e identificado, tornando-se consciente (2011). Na sequência do processo, as informações são então direcionadas para a amígdala cerebral “(...) Ela é um aglomerado de neurônios de organização complexa, que tem múltiplas conexões com outras áreas do sistema nervoso. Através dessas conexões a amígdala age como um centro coordenador (...)" (COSENZA E GUERRA, 2011, p.76-77).

Visto os argumentos biológicos acima, que destacam a amígdala como principal estrutura neuroanatômica que relaciona os sentidos e as emoções e, agregando-se a esses argumentos, é importante trazermos o que escreveu Sanchez Vasquez sobre o significado humano atribuído aos sentidos, que apesar de supor os órgãos sensoriais por suas estruturas e funcionamentos que constituem nossa natureza biológica, estes se distinguem devido seu caráter social. "Os sentidos surgiram antes de mais nada como resultado do desenvolvimento histórico-social do homem, da criação de um mundo objetivo e, por sua vez, da autocriação do homem mediante o trabalho" (Sanchez Vasquez, 1978, p.85).

Exemplificando o que entendemos serem as unidades de significado que expressam os EEC, formados a partir dos sentidos em suas bases biológicos e significados humanos, são trazidas as seguintes falas: "Durante a entrevista passamos por lugares indesejáveis por causa da sujeira, lixos nas ruas e esgotos a céu aberto. Aprendi vendo a exploração porque a necessidade fala mais alto" (E2.2.3); "Existem vários fatores que ligam nossos conteúdos com a realidade, um deles é a degradação ambiental que é muito visível onde vivemos" (E29.1.2); "Fazendo a pesquisa no bairro podemos encontrar Rev. Eetrônica Mestr. Educ. Ambient. Rio Grande, v. 36, n. 3, p. 43-64, set./dez. 2019. E-ISSN 1517-1256 
diversos fatores para nós termos uma nova consciência. Podemos encontrar pessoas passando muitas necessidades e revoltadas com nossos governantes” (E11.1.3).

As unidades de significado expressam diferentes reações sobre determinadas experiências vivenciadas durante o estudo da realidade. A partir do que traz Damásio (1994, p.168), e para as situações apresentadas nas falas acima, consideramos como sendo o EEC, “(...) a identificação da degradação ambiental presente na sociedade e sua relação com o ser humano". Justamente por fazer parte de toda a dinâmica social, A problemática ambiental é uma questão que não pode ser negligenciada pelas escolas e, entendemos ser um ponto fundamental que deve integrar os currículos escolares, trazendo a realidade e suas contradições para dentro do espaço escolar. Para que isso ocorra, o processo de estudo da realidade desenvolvido, primeira etapa do método de IT, apresenta-se enquanto um processo que efetiva essa integração entre escola e seu contexto circundante, pois estabelece o contato dos sujeitos participantes do processo com circunstâncias como as apresentadas nas falas acima.

Destacamos a fala que diz que "A realidade é tudo o que eu posso sentir, ver e observar, as vezes a realidade assusta, as vezes ignoramos pois é mais fácil ver TV, do que ver os problemas do mundo" (E19.1.3), e, entendemos que o estudo da realidade é uma estratégia significativa de ensino e pesquisa, pois possibilita o contato com as situações reais e não virtuais como as apresentadas em mídias digitais e livros, comumente utilizadas em sala de aula. A vivência da realidade se dá através dos seus múltiplos estímulos sensoriais o que, além de facilitar aprendizagens (SALOMÃO DE FREITAS, MOTTA e MELLO-CARPES, 2014), contribui para o reconhecimento da existência de problemas sociais e ambientais do contexto dos sujeitos do processo educativo, favorecendo relações que configuram a ação educativa como contextualizada. Compartilhando da nossa compreensão, destacamos que:

(...) os sentidos (re)construídos pelos aprendentes sobre seu contexto (que será o contexto em estudo) serão mais significativos na medida em que eles percebem outras relações existentes e as problematizam, procurando perceber o que produz o contexto, o que contribui para que este permaneça como está e as relações socio-historicamente estabelecidas que proíbem esse contexto de mudar - processo grávido de emoções e estímulos favoráveis para aquisição e evocação de memórias (SALOMÃO DE FREITAS, MOTTA e MELLO-CARPES, 2014, p.116117).

Rev. Eletrônica Mestr. Educ. Ambient. Rio Grande, v. 36, n. 3, p. 43-64, set./dez. 2019. E-ISSN 1517-1256 
As relações desiguais existentes no contexto investigado também se expressam nas falas que se seguem: "(a pesquisa da realidade) Acho que ajudou a ver o problema dos outros, pois só sabíamos ver os problemas que tinham em nosso bairro" (E5.4.1); "Eu sinto que a comunidade é muito carente de apoio, em tudo na saúde na segurança eu sinto que tem como melhorar, mas falta à comunidade se reunir e procurar reivindicar seus direitos" (E34.4.3). Assim como, na seguinte fala:

Quando saímos na comunidade podemos ver muitas dificuldades. Acredito que não temos como mudar isso, nem todo mundo em uma conscientização de termos o bairro limpo ou bonito, não adianta eu e meia dúzia querer a diferença e mais da maioria não se importar, só olhar para o próprio umbigo" (E21.1.4).

Nas falas acima reconhecemos enquanto EEC (DAMÁSIO, 1996, p.168) como sendo "o reconhecimento da condição humana e suas necessidades". Consideramos que o estudo da realidade, enquanto um processo educativo organizado, constitui-se como uma "experiência estética", pois, a partir deste, os participantes estabelecem outra relação com o contexto, uma relação sensível, estética ou, como define Damásio (2005), uma "experiência emocional" que “(...) inclui a percepção e identificação do produto, as associações e lembranças que ele ativa, os sentimentos e as emoções que ele evoca e os julgamentos que ele aciona” (DAMÁSIO, 2005, p.40).

Dessa forma, participar do estudo da realidade permite que estimulemos nossos sentidos ao nos relacionarmos com o contexto de uma forma estético-emocional quando sentimos o clima, pulamos suas valas, desviamos dos carros, vemos moradores sem as necessidades básicas, encontramos sorrisos afetuosos e dispostos a dialogar ou ainda, quando as respostas são desagradáveis e mostram uma realidade de sofrimento latente. Essa experiência estético-emocional ativa diferentes regiões cerebrais, associando características, sejam elas agradáveis ou desagradáveis. Essas informações são então transmitidas de forma integrada até centros específicos do cérebro (SALOMÃO DE FREITAS, MOTTA e MELLO-CARPES, 2014). Logo, "O cérebro, então, em suas zonas de memória, entre as quais podemos destacar o hipocampo, compara a informação recebida com uma informação prévia, auxiliando no controle da informação que uma pessoa aprenderá ou deixará de aprender (...)" (SALOMÃO DE FREITAS, MOTTA e MELLO-CARPES, 2014, p.116).

O que evidenciamos é que o estudo da realidade, enquanto etapa do método de IT freireana, apresenta-se como uma estratégia pedagógica, potencialmente capaz Rev. Eletrônica Mestr. Educ. Ambient. Rio Grande, v. 36, n. 3, p. 43-64, set./dez. 2019. E-ISSN 1517-1256 
contextualizar com a realidade aquilo que se estuda, visto que promove uma relação direta de estimulação de zonas e processos neuronais que irão favorecer a aprendizagem dos sujeitos envolvidos. Essa compreensão, de considerarmos o contexto e suas relações como forma de associar com o que se estuda é destacada por Damásio (1994) quando coloca que: “(...) muito embora a cultura e a civilização surjam do comportamento de indivíduos biológicos, esse comportamento teve origem em comunidades de indivíduos que interagiam em meios ambientes específicos" (DAMÁSIO, 1994, p.153).

A maneira como os estudantes percebem, de forma sensível, o contexto específico de realização do estudo da realidade é o que apresentamos na categoria a seguir.

\section{Percepção sensível do contexto investigado}

Nesse momento se faz necessário, de pronto, definirmos o entendimento de percepção. Para Lent, percepção é “(...) a capacidade de associar as informações sensoriais à memória e à cognição, de modo a formar conceitos sobre o mundo, sobre nós mesmos e orientar nosso comportamento" (LENT, 2001, p. 557). Nessa compreensão, a percepção se configura como um processo, em que se destacam os sentidos como via de acesso às informações do exterior e que conduzem o modo como agimos sobre e no mundo. Os fragmentos de fala dos estudantes participantes destacados com este sentido, são os seguintes: "Essa pesquisa é importante, pois nos ajuda a perceber coisas que talvez nós não tenhamos notado, encontrar soluções, se envolver com a realidade” (E22.1.1); "No momento da entrevista eu percebi que a realidade da comunidade é uma questão que deve ser bem discutida" (E1.4.1); "Através do diálogo percebemos coisas que não conseguimos ver" (E34.4.1); "No mundo em que estamos vivendo tá faltando educação, sensibilidade, amor e persistência, com educação podemos mudar tudo isso, mas de que adianta querer mudar, se quase todo o resto do mundo só quer estragar, não se importa com o outro?" (E5.1.1).

Essas falas nos mostram que o desenvolvimento do estudo da realidade possibilitou a percepção de aspectos que, normalmente, não seriam notados sem a intencionalidade investigativa. Sobre a percepção sensível, concordamos com o autor Sánchez Vázquez quando afirmou que: “(...) no comportamento cotidiano com as coisas que nos rodeiam e que utilizamos, a redução dos dados sensíveis é tão grande - dada a automatização perceptiva - que quase desaparecem” (1999, p. 143). Dessa forma, torna-se necessária a inclusão de práticas educativas que promovam a percepção sensível da realidade. Para Rev. Eletrônica Mestr. Educ. Ambient. Rio Grande, v. 36, n. 3, p. 43-64, set./dez. 2019. E-ISSN 1517-1256 
tanto, apostamos na investigação da realidade como uma prática de investigação sensível, desvelando problemas sociais $\mathrm{e}$ ambientais, que passam a integrar as abordagens realizadas em sala de aula.

As falas que apresentamos a seguir referem-se à percepção das pessoas e suas aspirações em relação à comunidade: "E eu percebi que as pessoas não estão muito contentes com as coisas que estão acontecendo em volta. A maioria das pessoas tem esperança que as coisas em nossa comunidade melhore" (E33.4.1); "Eu percebi que as pessoas estão mais dispostas a lutar por seus direitos" (E34.4.2); "Sentimos que as pessoas estão um pouco desmotivadas em relação às políticas públicas" (E18.4.1); "Percebi confiança nas entrevistadas, e parece que elas ainda têm esperança que o bairro melhore" (E21.4.3).

Apesar das falas mostrarem diferentes aspectos percebidos, evidenciam a sensibilidade com que as pessoas se relacionam com o contexto em que vivem, mostrando-se ora descontentes e/ou desmotivadas, ora confiantes e/ou esperançosas. Isso indica que, a percepção das reações sensíveis das pessoas depende de cada situação e história, as quais condicionam a forma como se relacionam com a realidade. Segundo Damásio (1996), o organismo é alterado constante e ativamente em busca das melhores possibilidades de adaptação, reagindo ao meio em que está inserido, provocando mudanças permanentes nos sujeitos. $\mathrm{O}$ autor ainda sugere que a percepção, de modo geral, inclui também as reações emocionais relacionadas à determinada experiência perceptiva (DAMÁSIO, 1994).

Sanchez Vasquez (1978) nos diz que a relação estética dos sujeitos com a realidade, como uma relação de transformação social, não cria apenas os objetos que o ser humano é capaz de transformar, mas cria o sujeito que transforma o objeto. Para tanto, quando os sujeitos estão imersos no processo de estudo da realidade, estabelecendo uma relação estético-emocional, estamos nos transformando, nos tornando mais críticos, pois somos capazes não só de perceber e nos distanciarmos das situações, mas de nos questionarmos sobre quais forças condicionaram a existência das contradições percebidas e ainda, projetar uma realidade diferente, reconhecendo nosso potencial transformador.

Bispo (2003) ao descrever a sequência neural da percepção afirma que o processo seria iniciado quando um objeto é percebido pelo organismo, quando essa percepção ativa circuitos cerebrais e esses estimulam mudanças fisiológicas no funcionamento do corpo, o que corresponde às emoções. A ativação mencionada, bem como as mudanças percebidas por outros circuitos cerebrais correspondem ao que compreendemos com sendo o Rev. Eletrônica Mestr. Educ. Ambient. Rio Grande, v. 36, n. 3, p. 43-64, set./dez. 2019. E-ISSN 1517-1256 
sentimento, logo “(...) um padrão neuronal de segunda ordem tem lugar, reunindo a percepção do objeto percebido inicialmente e a percepção das mudanças na paisagem corporal, formando o que conhecemos por consciência (...)" (BISPO, 2003, p.296).

Assim, consideramos pertinente apresentar e refletir sobre as falas, referentes à percepção sensível, pois esse processo compõe a sequência de atividades neuronais que formam as emoções, o que integra a categoria posterior.

\section{O reconhecimento das emoções a partir da experiência estética de estudo da realidade}

Para construirmos essa categoria, concentramos nossos esforços investigativos buscando indícios de emoções, expressos nas falas dos estudantes em relação ao estudo da realidade. Para iniciarmos essa abordagem, assumimos emoções como sendo as reações biorregulatórias que têm o objetivo de promover estados fisiológicos constituídas por um conjunto de respostas químicas e neuronais organizados em padrões pelo cérebro. Tais reações resultam em respostas que são produzidas quando o cérebro detecta um EEC cuja presença real ou relembrada desencadeia a emoção (Damásio, 1996; 2003; 2005).

As emoções apresentam caráter biológico-evolutivo, sendo respostas aos diferentes estímulos, necessárias para a adaptação ao meio. Classificam-se de acordo com a sua complexidade evolutiva e interdependência em: emoções de fundo, emoções primárias e emoções secundárias/sociais (DAMÁSIO, 2003). As emoções de fundo estão relacionadas com o estado do corpo e são induzidas por estímulos internos, com origem em processos físicos ou mentais. Nesse tipo de emoção, o papel principal é desempenhado pelo meio interno e pelas vísceras. As emoções primárias envolvem disposições inatas ou reflexas para responder a certas classes de estímulo, controladas pelo sistema límbico. As emoções secundárias/sociais são aprendidas de acordo com a cultura na qual convivemos e envolvem categorizações de representações dos diferentes estímulos, associadas a respostas anteriormente vividas e reavaliadas. O córtex cerebral é o substrato neural das emoções sociais, mas a expressão dessas emoções também envolve as estruturas do sistema límbico (DAMÁSIO, 1994; 2003). O autor exemplifica as emoções secundárias como sendo: a simpatia, a compaixão, o embaraço, a vergonha, a culpa, o orgulho, o ciúme, a inveja, a gratidão, a admiração e o espanto, a indignação e o desprezo. (DAMÁSIO, 2003, p.54). 
As emoções, de forma geral, são formadas considerando as seguintes etapas: 1) avaliação do EEC pelos córtices de associação; 2) desencadeamento do processo de percepção neuronal que acontece na amígdala; 3) execução que leva a um estado emocional e ocorrem no prosencéfalo basal, hipotálamo e tronco cerebral, resultando no estado emocional que são alterações transitórias no meio interno; vísceras; sistema muscular e ainda, comportamento e associação de imagens mentais (DAMÁSIO, 2003).

Sobre as reações emocionais, concordando com o autor supracitado:

Vejo a essência da emoção como a coleção de mudanças no estado do corpo que são induzidas numa infinidade de órgãos por meio das terminações das células nervosas sob o controle de um sistema cerebral dedicado, o qual responde ao conteúdo dos pensamentos relativos a uma determinada entidade ou acontecimento. Muitas das alterações do estado do corpo - na cor da pele, postura corporal e expressão facial, por exemplo - são efetivamente perceptíveis para um observador externo. (...) Existem outras alterações do estado do corpo que só são perceptíveis pelo dono desse corpo. Mas as emoções vão além da sua essência. (DAMÁSIO, 1994, p.168. Grifos nossos).

Os indícios de emoções foram identificados como reações emocionais, retomadas de memórias expressas em escritas reflexivas. Essas escritas evidenciam como os estudantes se sentiram, diante de determinadas situações no processo de estudo da realidade e que, de acordo com o que foi evidenciado nos parágrafos anteriores, podemos classificar, ainda que de forma incipiente, como emoções. Ao construirmos esta categoria, conseguimos identificar determinadas emoções, como é o caso das falas a seguir, que expressam a emoção de tristeza: "Senti um sentimento de tristeza, onde foi relatado mais coisas ruins do que boas, nosso comportamento foi muito bom, respeitamos as pessoas como gostaríamos de ser tratados" (E24.4.2). Complementado pelas falas seguintes:

Fico triste porque se todos colaborassem o bairro não seria considerado um bairro de muita pobreza e de pessoas marginalizadas. Me afeta, no momento em que basta dizermos onde moramos que as pessoas ficam meio receosas como se não morassem pessoas civilizadas (E18.4.2);

Nós esperávamos encontrar, respostas e informações e lá encontramos, eu fiquei chocado com algumas situações, tais como sem iluminação e algumas pessoas não sabiam o que falar só davam risada naquele momento eu vi a falta de interesse de algumas pessoas e fiquei triste com isso como uma pessoa pode morar em um bairro e não saber o que vê de bom na comunidade (E28.4.1).

As falas evidenciam a emoção de tristeza, em relação a situações experienciadas e mostram como a realidade afeta as pessoas, de forma negativa. Apesar da unidade de 
significado do estudante E24.4.2 se referir como sentimento, entendemos que esta referese a uma emoção. A tristeza, juntamente com a alegria, o medo, a raiva, a surpresa e a repugnância, compõem as emoções básicas (DAMÁSIO, 2003). O autor ainda afirma que "A essência da tristeza ou da felicidade é a percepção combinada de determinados estados corporais e de pensamentos que estejam justapostos, complementados por uma alteração no estilo e na eficiência do processo de pensamento" (DAMÁSIO, 1994, p.175).

Ao transcorrermos as falas acima, compreendemos que o contato com determinadas situações fez com que os estudantes reagissem emocionalmente com tristeza. Porém, o fato dos estudantes se entristecerem torna significativo quando estes estão conscientes das situações que os deixaram tristes, ou seja, reconhecemos aquilo que os alegra ou entristece, aquilo que os sensibiliza, que desperta emoções por diferentes significados, humanamente construídos, em relação às situações emocionalmente competentes. Sobre isso Damásio dirá que "Graças ao controle da nossa interação com os objetos que causam emoções conseguimos exercer algum controle sobre o nosso processo de vida e conseguimos levar o nosso organismo a um estado de maior ou menor harmonia (...)" (DAMÁSIO, 2003, p. 60).

$\mathrm{Na}$ sequência, evidenciamos a relação de interação trazida na citação anterior e exemplificamos com as falas seguintes, que expressam emoções de alegria, motivação e tranquilidade; reações à realidade estudada pelos estudantes: "Me senti feliz, em saber que se sentiram a vontade de dividir um pouco de seu tempo conosco" (E21.4.2); “O que me motiva a ir em busca de um emprego é a necessidade de ter meu próprio dinheiro e também de construir um futuro melhor" (E1.2.1). Expresso também na unidade que diz:

Eu me senti tranquilo e bem a vontade, pois pensei que nem seriamos atendidos por ser de noite e as pessoas estarem cansadas, sem falar que esta pesquisa foi feita nos 3 turnos, mas fui surpreendido, fomos muito bem recebidos, eu nem estranhei a realidade que vi, pois eu moro aqui, mas já as resposta das perguntas me fizeram ter um pensamento mais amplo e critico, pois quando ouvíamos novos pontos vista sobre tal assunto nós mesmo nos fizemos uma autoavaliação para mudar algumas ideias que tínhamos antes com pouco conhecimento (E22.4.1).

Segundo Damásio, as emoções desempenham função social e papel decisivo no processo de interação e integração sociais, “(...) as emoções acabam por ajudar a ligar a regulação homeostática e os 'valores' de sobrevivência a muitos eventos e objetos de nossa experiência autobiográfica" (DAMÁSIO, 2003, p. 80). Para tanto, a "experiência autobiográfica" mencionada anteriormente, que qualifica a história de cada sujeito, será 
um fator imperativo na maneira com que nos relacionamos e tomamos as decisões, em face à realidade. Ao produzirem os registros escritos - aqui evidenciados como falas- os estudantes tiveram que retomar essas alterações de estado do corpo, remetendo-se às lembranças emocionais do momento do estudo da realidade. Suas falas - supracitadas revelaram alegria, e motivação, em contraposição às falas anteriores, que indicaram tristeza, o que mostra a diversidade de maneiras com que interagimos com as situações, além do modo como representamos nossa relação com a realidade.

Apresentamos mais exemplos das falas que, também, exemplificam a relação emocional diversa que o estudo da realidade é capaz de proporcionar nos estudantes. As falas, a seguir, mostram emoções de medo, pena e ainda o reconhecimento da emoção de desprezo (repugnância), a partir do diálogo com as pessoas da comunidade: "Eu senti dó das pessoas é porque é muito triste a situação da comunidade” (E06.4.1); "As pessoas nos receberam "super" bem, exceto uma senhora que nos tratou com frieza, porque ela nos disse que se adiantasse nós andar fazendo perguntas, não teria tanto lixo, tantos problemas na comunidade, etc" (E05.4.1); "O meu sentimento é o de pavor eu sei que éo mesmo, é um sentimento de raiva porque pagamos um absurdo de impostos e não temos retorno não temos saneamento básico, iluminação e esgoto em frente a nossas casas" (E12.4.2). A fala do estudante seguinte também expressa a relação emocional dos sujeitos com o ambiente, afirmando que:

Então hoje a nossa realidade é bem diferente, um pouco arriscada e até da medo de enfrentá-la as vezes. Conversar com as pessoas, as vezes nos dá a oportunidade de desenvolver aquele assunto, e ajudar as pessoas a terem uma nova consciência daquilo ou uma nova visão (E17.1.3).

Primeiramente, reportamo-nos a fala do estudante E12.4.2 que, apesar de se referir como sendo um sentimento o que ele sentiu, trata-se de um estado emocional conforme afirmou Damásio (1994). Em relação ao que foi dito acima, destacamos a experiência individual dos sujeitos que incide sobre os modos como estes se relacionam com os objetos/situações, podendo provocar emoções, ainda que antagônicas, mas interdependentes, como a alegria e a tristeza. Esse antagonismo é valorado como belo ou feio, e terá significado específico para cada ser humano, a partir do seu caráter emocional. Para Sanchez Vazquez (1999) “(...) é válido afirmar que todo belo é estético, mas nem todo estético é belo" (p. 39). Ou seja, existe um componente estético-emocional, com bases neurobiológicas e construtos sociais, históricos e culturais, que media nosso contato 
com a realidade. Damásio (2003, p.63) expressa que "Alguns dos objetos são emocionalmente competentes por razões evolucionárias"; no entanto a grande maioria dos objetos se transformam em estímulos emocionais competentes no curso das nossas experiências individuais "É muito dificil imaginar objetos emocionalmente neutros. Os objetos emocionalmente competentes podem estar presentes na realidade atual ou ser recuperados da memória (...) se o estímulo tem competência emocional segue uma emoção" (DAMÁSIO, 2003, p.63-64).

As emoções estão não somente relacionadas às formas com que agimos sobre a realidade, mas são indispensáveis para que, a partir dessa relação emocional, escolhemos como agir sobre o mundo, o que “(...) está intrinsecamente vinculada à nossa percepção sensível e à nossa entrelaçada rede de sentimentos, valores e pensamentos próprios de cada um de nós enquanto indivíduos" (SILVEIRA, 2015, p.132-133). Assim, as emoções são mobilizadoras dos modos de ser e estar no mundo, podendo mobilizar os estudantes em relação à determinada atividade educativa, contribuindo com o processo de ensinoaprendizagem de forma integral, sendo tão mais significativa essa contribuição quando se experiencia o contexto real, vivido e sentido em todas suas nuances, contraditoriamente marcadas por componentes estéticos.

As emoções, ainda, desencadeiam o processo de formação de sentimentos, que na compreensão de Damásio (1994), “(...) todas as emoções originam sentimentos, se estiver desperto e atento, mas nem todos os sentimentos provêm de emoções" (DAMÁSIO, 1994, p.172). Os sentimentos gerados pelas emoções são chamados pelo autor citado de "sentimentos emocionais", que se baseiam nas emoções para sua formação ou evocação das memórias que produzem determinado sentimento. Neste trabalho não faremos uma abordagem em relação ao sentimento, por não ser o foco da nossa intenção com o estudo, porém destacamos a importância da sua compreensão para melhor entendermos sua influência nos processos que permeiam a educação, aproximando-a das Neurociências.

Nesta etapa do estudo, finalizamos a discussão construída que buscou relacionar fundamentos neuronais dos EEC, percepção sensível e emoções com os fundamentos estético-ambientais da Educação. Ao que se segue, apresentamos as considerações finais, sintetizando o que foi abordado e apontando perspectivas, possibilidades e limitações do estudo.

\section{CONSIDERAÇÕES FINAIS}

Rev. Eletrônica Mestr. Educ. Ambient. Rio Grande, v. 36, n. 3, p. 43-64, set./dez. 2019. E-ISSN 1517-1256 
A presente pesquisa apresentou os resultados da investigação de indícios de estímulos emocionalmente competentes e emoções provocados por um estudo da realidade, primeira etapa do processo de Investigação Temática freireana, fundamentado numa perspectiva estético-ambiental da educação, a fim de argumentar sobre a relevância de práticas educativas de investigação que considerem os aspectos neurobiológicos dos sujeitos. Os sujeitos envolvidos em um processo educativo necessitam experienciar as situações reais, sentindo seus estímulos de forma a perceber sensivelmente, e assim, mobilizarem-se na transformação da realidade estudada. Acreditamos que objetivo foi atingido, pois puderam ser evidenciadas falas que trouxeram aspectos que as identificam enquanto reações emocionais produzidas no desenvolvimento do estudo da realidade.

Retomando o argumento construído ao longo do artigo, ressaltamos que a problemática ambiental deve, preponderantemente, integrar os currículos escolares, inserindo a realidade e suas contradições no espaço escolar. Com o estudo, ainda conseguimos perceber a transformação da consciência dos sujeitos envolvidos, quando estes foram capazes de reconhecer situações que antes se apresentavam como naturalizadas e, ao dialogarem com outros moradores da comunidade estudada, puderam ser evidenciadas as contradições e condições de vida de muitas pessoas. Dessa forma, participar do estudo da realidade, permitiu que estimulemos nossos sentidos ao nos relacionarmos com o contexto de uma forma estético-emocional.

O que defendemos, é a inclusão de práticas educativas que promovam a percepção sensível da realidade, pois, ao nos lançarmos sobre a realidade de forma investigativa e esta promover emoções, estamos nos tornando cada vez críticos, ampliando nossa consciência de mundo. Nossa percepção sobre a realidade nos faz questionarmos as forças que condicionam a existência das contradições percebidas e, ainda, mobiliza-nos a projetar uma realidade diferente, reconhecendo nosso potencial transformador. A transformação é efetivada quando nos mobilizamos, agindo ao repensarmos nossos modos de ser e estar no mundo, contribuindo com o processo de ensino-aprendizagem de forma holística, sendo a vivência do contexto real, sentida em todas suas dimensões, permeadas de estímulos estéticos e, logo, emocionais.

Para dar continuidade, aperfeiçoando e ampliando este estudo, projetamos que outras práticas de estudo da realidade sejam investigadas, considerando as demais etapas do método de IT, como balizador dos estudos de articulação com a realidade, assim como o fundamento estético-ambiental da Educação, permitindo que nos mantenhamos conscientes do nosso papel de professores, que assumem a responsabilidade de fazer da Rev. Eetrônica Mestr. Educ. Ambient. Rio Grande, v. 36, n. 3, p. 43-64, set./dez. 2019. E-ISSN 1517-1256 
sua prática, um espaço em que as pessoas se sintam felizes, amadas e críticas, inovando o saber-fazer pedagógico.

\section{REFERÊNCIAS}

BISPO, Ronaldo. O sentimento do sentimento do que nos acontece: a consciência em Damásio. Galáxia: Revista do Programa de Pós-Graduação em Comunicação e Semiótica, São Paulo, s/v, n.5, p.293-299, 2003. Disponível em: https://revistas.pucsp.br/index.php/galaxia/article/view/1328/822. Acesso em: 10 de ago. de 2019.

BRASIL. Ministério de Educação. Conselho Nacional de Educação. Câmara de Educação Básica. Resolução no 4/2010: Define Diretrizes Curriculares Nacionais Gerais para Educação Básica. Brasîlia: CNE, 13 jul. de 2010a.

BRASIL. Ministério de Educação. Conselho Nacional de Educação. Câmara de Educação Básica. Parecer 7/2010:Diretrizes Curriculares Nacionais Gerais para a Educação Básica. Brasillia: CNE, 07 abr. de 2010b.

COSENZA, Ramon M.; GUERRA, Leonor B. Neurociência e educação: como o cérebro aprende. Porto Alegre: ArtMed, 2011.

DAMÁSIO, António. O erro de Descartes: emoção, razão e o cérebro humano. São Paulo: Companhia das letras, 1996.

DAMÁSIO, António. Em busca de Espinosa: prazer e dor na ciência dos sentimentos. São Paulo: Companhia das letras, 2003.

DAMÁSIO, António. E o cérebro criou o Homem. São Paulo: Companhia das Letras, 2005.

DAMIANI, Magda Floriana; ROCHEFORT, Renato Siqueira; CASTRO, Rafael Fonseca de.; DARIZ, Marion Rodrigues; PINHEIRO, Silvia Siqueira. Discutindo pesquisa do tipo intervenção. Cademos de Educação, Pelotas, v. 45, n.3,p 47-67, jul/ago. 2013. Dispinível em: https://periodicos.ufpel.edu.br/ojs2/index.php/caduc/article/view/3822/3074. Acesso em: 20 de set. de 2019.

ESTÉVEZ, Pablo René. Lo Estético em la Educación Popular. Educación, La Habana, v. 1, n. 141, p.22-28, jan/abr, 2014a.

ESTÉVEZ, Pablo René. Enseñar a sentir. Educación, La Habana, v.1, n.143, p.33-40, mai/ago, 2014b.

FREIRE, Paulo. Pedagogia do Oprimido.50.ed. Rio de Janeiro: Paz e Terra, 2011.

LENT, Roberto. Cem bilhões de neurônios: conceitos fundamentais da neurociência. São Paulo: Atheneu, 2001. 
MINAYO, Maria Cecília de Souza. Pesquisa social: Teoria, método e criatividade. Petrópolis:Vozes, 1994.

MORAES, Roque.; GALIAZZI, Maria do Carmo. Análise Textual Discursiva. Ijuí: Editora da Unijuí. 2007.

MUNHOZ, Silmara Carina Dornelas; ZANELLA, Andréa Vieira. Linguagem escrita e relações estéticas: algumas considerações. Psicologia em Estudo, Maringá, v.13, n.2, p.287-295, abr/jun. 2008. 2 Disponível http://www.scielo.br/pdf/pe/v13n2/a11v13n2.pdf. Acesso em: 15 de ago. de 2018.

PPP. 2013. Projeto Político Pedagógico. Secretaria de Educação do estado do Rio Grande do Sul.

SALOMÃO DE FREITAS, Diana Paula; MOTTA, Cezar Soares; MELlO-CARPES, Pâmela Billig. As bases neurobiológicas da aprendizagem no contexto da investigação Temática freireana. Revista Trabalho, Educação e Saúde, Rio de Janeiro, v. 13 n. 1, p. 109-122, jan./abr. 2014. Disponível em: http:/www.scielo.br/pdf/tes/v13nl/1981-7746tes-1981-7746-00023.pdf. Acesso em: 10 de ago. de 2018.

SÁNCHEZ VÁZQUEZ, Adolfo. As ideias estéticas de Marx. Rio de Janeiro: Paz e Terra, 1978.

SANCHEZ VÁZQUEZ, Adolfo. Um convite à estética. Rio de Janeiro: Civilização Brasileira, $1999.336 \mathrm{p}$.

SILVEIRA, Wagner Terra. O fundamento estético na Educação Ambiental Transformadora. Curitiba: Appris, 2015.

VASCONCELLOS, Celso dos S. Metodologia dialética em sala de aula. Revista de Educação AEC. Brasilia, v.21, n.83, p.28-55. abr./Jun., 1992. Disponível em: http://www.celsovasconcellos.com.br/Textos/MDSA-AEC.pdf. Acesso em: 15 de set. de 2018 .

LOUREIRO, Carlos Frederico Bernardo. Sustentabilidade e Educação: um olhar da ecologia política. Editora Cortez, 2012. 